In Proceedings of the 8th European Conference of Computer-supported Cooperative Work (ECSCW'05), September 18-22, 2005, Paris, France.

\title{
Managing currents of work: Multi-tasking among multiple collaborations
}

\author{
Victor M. González, Gloria Mark \\ Department of Informatics, University of California, Irvine. U.S.A. \\ \{vmgyg, gmark\}@ics.uci.edu
}

\begin{abstract}
This research reports on a study of the interplay between multi-tasking and collaborative work. We conducted an ethnographic study in two different companies where we observed the experiences and practices of thirty-six information workers. We observed that people continually switch between different collaborative contexts throughout their day. We refer to activities that are thematically connected as working spheres. We discovered that to multi-task and cope with the resulting fragmentation of their work, individuals constantly renew overviews of their working spheres, they strategize how to manage transitions between contexts and they maintain flexible foci among their different working spheres. We argue that system design to support collaborative work should include the notion that people are involved in multiple collaborations with contexts that change continually. System design must take into account these continual changes: people switch between local and global perspectives of their working spheres, have varying states of awareness of their different working spheres, and are continually managing transitions between contexts due to interruptions.
\end{abstract}

\section{Introduction}

Collaboration among information workers has long received attention in CSCW. However, a new perspective is now beginning to focus on information work: people's involvement in a multitude of projects and initiatives (Belloti et al. 2004; Czerwinski et al. 2004; Fussell et al. 2004; Mark et al. 2005). In fields as diverse 
as finance, software development, consulting, and academia, we are finding that it is commonplace that information workers are involved in multiple collaborations that occur in parallel. This demands that individuals enact specific efforts to coordinate, manage and track those collaborations and the activities associated with them.

Viewing a person's work in terms of multiple collaborations has particular relevance for the field of $\mathrm{CSCW}$. Most CSCW studies of office work have focused on sole collaborations, in both distributed or collocated environments, too numerous to list here (e.g. Ackerman et al. 1997; Mark et al. 1999; Rogers 1994; Rouncefield et al. 1994) Other studies though, that recognize that people are involved in multiple and simultaneous projects, have not consolidated findings in order to identify strategies that individuals use to cope with the demands of multiple collaborations and activities (Buscher et al. 1999). Therefore, following this perspective that people must manage multiple activities, we propose to examine collaboration not as an isolated experience in a particular context but rather as an ongoing stream of activities where people move in and out of different collaborative contexts based on circumstances.

Focusing on multiple collaborations leads us to ask how information workers can manage their different collaborations over the course of a day. We are interested in examining how people manage transitions among activities and how they maintain continuity when their activities are fragmented.

In this paper we present the results of an analysis of the multi-tasking practices of thirty-six information workers as they were observed in situ. Based on this analysis, we argue that individuals adopt particular strategies that enable them to manage their work while multi-tasking. These strategies include a constant renewal of overviews of their various collaborations, managing transitions as these collaborative contexts change and maintaining a flexible window of focus across activities.

\section{Related work}

Previous studies have recognized that information workers are typically involved in multiple activities and collaborations (Hudson et al. 2002; Perlow 1999; Sproull 1984). It has been argued that the need to multi-task seems to be increasing as companies increasingly more experience a flattening of organizational hierarchies, adopt team-oriented forms of organization, constantly change organizational structures, relax the formalization of job roles, and demand employees to focus on multiple and varied initiatives (DiMaggio 2001). The nature of work today for many information workers resembles what used to be exclusive to top-level managers, i.e. characterized by fast-paced and varied activities, frequent fragmentation of actions and constant interpersonal interactions (Mintzberg 1973). 
Many studies have highlighted that information workers often experience interruptions during the execution of their activities (O'Conaill and Frohlich 1995; Rouncefield et al. 1994). Due to the accessibility of other co-workers, people often find themselves engaged in informal interactions thematically unrelated with the activity they were working on before an interruption. It is recognized that collaborative work demands these kinds of interactions as they serve both social and work oriented functions, and fundamentally, they serve as flexible mechanisms to cope with changing circumstances and problem-solving (Kraut et al. 1993; Whittaker et al. 1994).

How information workers cope with the management of multiple activities and interruptions is still not well understood. It is often said that multi-tasking involves the management of a set of diverse aspects such as time, contacts, documents or even physical space (Belloti et al. 2003; Blandford and Green 2001; Boardman and Sasse 2004). However, it is not clear how, in practice, individuals can juggle priorities and what strategies they use to achieve this.

\section{Collaborations and working spheres}

Distinguishing between the collaborative relationships that individuals establish and the practical activities involved in those collaborations is a starting point for understanding multi-tasking. For example, in order to design a software component a developer can establish a collaboration with a business analyst who is particularly knowledgeable about the subject. In this collaboration, they will divide their labor for the specification, design, implementation and testing of the component. The practical activity of developing a particular software component creates a collaboration among those two individuals. Thus, as individuals define the demands of their practical activities, they also define collaborations with relevant individuals.

We refer to these practical activities that individuals pursue as working spheres. Thus, a working sphere is a unit of work that serves to describe work efforts that people pursue in practice in order to meet their responsibilities. A working sphere can refer to short-term tasks, such as fixing a software component, routine work such as daily maintenance of equipment, events such as a provider's exhibition, or long-term projects such as implementing a new infrastructure for a client. More precisely, we define a working sphere as a unit of work that, from the perspective of the individual, has a unique time frame, involves a particular collaborative structure, and is oriented towards a specific purpose (González and Mark 2004). As a unit of work, a working sphere 
thematically connects sets of actions enacted by an individual such as phone calls, working on documents, e-mail messages, interactions, and so on ${ }^{1}$.

Collaborations clearly are often based on more than one working sphere. In some cases, individuals maintain a collaboration across time as they become involved in sequential working spheres (e.g. working on different software components which are part of a sustained long-term project). In other cases, collaborations demand simultaneous involvement in working spheres that have different purposes, time frames or collaborative structures. For example, the developer and analyst in the previous example can be simultaneously involved in two different working spheres: the development of a software component to be shipped by the end of the month and the evaluation of a new financial product to be completed by the end of the week.

Considering both the collaborations and the working spheres that individuals are involved in suggests that multi-tasking involves not only managing and keeping track of working spheres, but also managing the collaborations related to working spheres.

\section{Research setting and methodology}

The analysis presented here is based on an empirical investigation aimed to understand the strategies that information workers use to manage multiple activities. As opposed to taking a managerial perspective on work as in, e.g. (Sproull 1984), for our research we are especially interested in analyzing the practices of different kinds of information workers, with different roles in the organization and different levels of involvement in projects. Our investigation was conducted in two different companies. ITS is a company that acts as an outsourcer providing information technology and administrative services for major financial bond management companies. The size and volume of operations of their current client, CORI, demands that ITS serve them exclusively, currently having no other clients. Within ITS we observed informants working in two different teams. The JEB team focuses on supporting the financial systems used by the brokers in CORI. The AUG team focuses on the administrative operations managed in behalf of CORI, supporting the systems used to transfer money to financial institutions and the consolidation of accounts. The other study was conducted at Venture, a company specializing in providing specialized consulting services to small and medium-size medical practices. Hundreds of medical

\footnotetext{
1 Compared with other types of conceptualizations, a working sphere is closer to the notion of activity as defined by Activity Theory, in the sense of connecting sets of actions toward particular objects (Leont'ev, 1978). However the notion of working sphere lacks an emphasis on high-level motives as the notion of activity does (e.g. becoming a project leader) and focuses instead on practical short-term purposes (e.g. enrolling and attending the training sessions on leadership).
} 
practices around the U.S are currently using a proprietary software solution provided by Venture, which covers their billing, financial and administrative needs. At Venture we observed people from many different teams.

Thirty-six informants participated in our study. Fourteen informants were observed in the JEB team, ten in the AUG team and eleven in Venture. The set of informants covered personnel in varied positions and job roles including eleven managers, three project leaders, nine financial-business analysts, eight software developers, three support engineers, and two sales executives. In total, the study comprised more than 920 hours of systematic observation with an average of about 26 hours per informant.

Each informant was systematically observed, using a shadowing technique similar to the one used by Mintzberg (1973), during a minimum of three working days, and then was extensively interviewed. For the observation, a researcher sat with the informant at her cubicle and followed her to formal and informal meetings or other activities outside the cubicle whenever it was possible. The researcher used a time watch and notepad to record details of any actions performed by the individual and the activities towards which those actions were directed. Details such as the topic and fragments of conversations, people participating, and documents and applications involved, were carefully recorded with as much precision as possible. At the end of each day, or during breaks (e.g. lunch), informants were asked for clarifications about some of the actions observed. Data collected from each informant include transcripts of interviews, reports of observation, field notes, pictures and other documents.

The data were analyzed through a comparative analysis using grounded theory (Strauss and Corbin 1998). Through coding our data, we contrasted the behavior, experiences and strategies for multi-tasking among our informants, and produced a set of conceptual categories that consolidated our understanding about processes explaining multi-tasking. Data were also analyzed to identify the time duration and frequency of the working spheres that individuals engaged in.

The identification of working spheres was based on combining different sources of information. First, the informants themselves knew that we aimed to identify the different things they were working on each day. That influenced some individuals to naturally verbalize about some of their working spheres as they performed their work, without explicitly requesting them to do so. Sometimes at the beginning of the day they mentioned what they were planning to do; other times during the day they pointed out the purpose of the things they were doing. A second source resulted from the comments made by informants while interacting with co-workers. They referred to the things they were doing at the moment, e.g.: "As soon as I'm done with the ATRACK stuff I will move over the R6 spec" or "I cannot take it right now, I am attending the Jim's production issue". These comments were noted. A third source of data came from informal short interviews conducted with the informants at the end of each day, which 
served to clarify events and interactions. This part was emphasized on the study with the AUG team at ITS and at Venture, where we used a paper format that informants completed each day by listing the things they worked on. Finally, a fourth source of information came from the post-observation interviews in which we inquired about the working spheres observed.

\section{Characteristics of multi-tasking: a scenario}

To illustrate how our informants multi-task, we present a scenario that describes the dynamics of their involvement in multiple collaborations and working spheres during a morning. The following scenario, taken directly as it was observed, illustrates the experiences of David, a manager at ITS:

At 8:40 a.m., while preparing documents for a 9:00 a.m. meeting about SIGMA, David notices a new email from Steven, a business analyst from CORI, the ITS client. David expected a message from Steven in regards to R6, a major software release scheduled for the next quarter, but this e-mail is about another issue: Steven is having problems getting reports from the Blotter-system that David supervises. This issue becomes an additional unexpected working sphere that David will have to attend to this day. He calls Steven to find out more about the problem. After talking to him, he phones Phil, a developer in his team to explain the problem and explore some solutions. While talking to Phil, David is interrupted by the sudden presence of his boss Marti and Andrew who come with a question about the official holidays for the office in Munich, Germany. David was involved with Munich's operations earlier, but this working sphere is now peripheral for him as they only seek his opinion. At 9:03, David politely stops the conversation and leaves for his SIGMA meeting. He passes by Phil's cubicle and calls him as he is also involved in this initiative and is attending the meeting. Forty-five minutes later at 9:48 a.m., he is back and ready to continue his investigation on the Blottersystem but after looking briefly at Steven's message, Phil and Gian show up in his office with questions about a different project. At 11:00 a.m., he is alone again, returns to the email from Steven, and phones Shin, a database administrator. During the previous conversation, Phil pointed to Shin as the right person to help solve the problem. While talking to Shin, he says: "I will call you later", as he notices the presence at his office door of people from the TGS team and he turns to attend to them. At 11:31 a.m., he runs over to his boss's office to discuss about the GAPS initiative, another working sphere that is central to him, as he has responsibility for it. At 11:38 a.m., he is back in his office, checks his voice mail message, and listens to a message from Shin. It seems that the source of the problem was identified and Shin is asking David to contact Mike, another UNIX administrator, who Shin believes can fix the problem. He decides to go with Phil and together they go to talk with Mike.

This description of one of David's mornings serves to illustrate how his work is characterized by the constant switching between expected and unexpected working spheres. As other studies of office work have described (e.g. Suchman and Wynn 1984), we noticed that the situated nature of David's work led him to adjust his plans to cope with changing circumstances. Thus, David handled a stream of working spheres that included previously defined ongoing efforts (e.g. the SIGMA initiative), but also unexpected requests to solve problems (e.g. the Blotter-system) or to provide consultation for colleagues (e.g. questions about the 
Munich office). This constant switching among expected and unexpected working spheres led David's work to be quite fragmented.

A graphical representation of all David's activities on that day illustrates the degree of fragmentation and the constant transitioning back and forth among different working spheres. In figure 1, we distinguish between normal working spheres that are attended to in a non-expedited fashion and urgent working spheres, attended to promptly. We found that some problems faced by people at ITS were very urgent compared to others, e.g. the Blotter-issue, because they jeopardized CORI's operation with the risk of potential major financial losses. David, due to problems with some servers, had to engage in three urgent working spheres later that day. We also distinguish between central working spheres where the individual is more involved in the collaboration and responsible for the outcomes versus peripheral working spheres in which one's involvement in the collaboration is limited. For instance, a working sphere such as SIGMA represents for David a central area of concern as he is leading efforts within his team. In contrast, David's involvement in the Munich working sphere is peripheral as he is asked to help due to his expertise. His involvement was limited as shown by the brief conversation he had with Mike and Andrew.

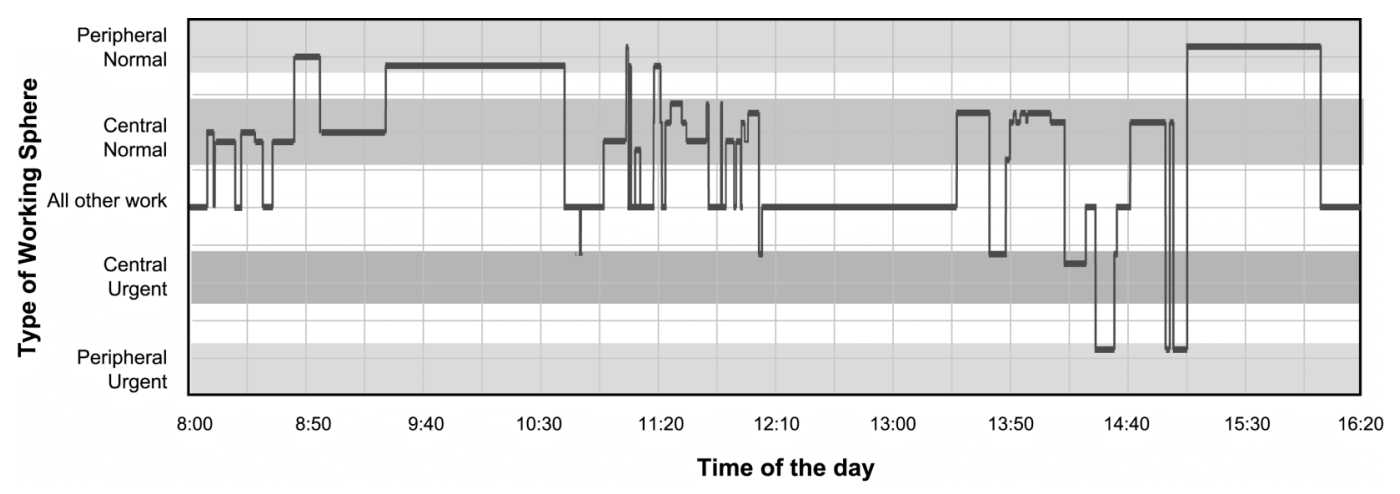

Figure 1. Map of David's activities in working spheres throughout the day.

We found that David experienced rapid switching among working spheres at certain points of the day. In total, he engaged in 14 different working spheres, nine that were central for him, and five with peripheral involvement. Of those working spheres, three were urgent. His involvement with workings spheres is characterized by brief segments of continuous engagement in each sphere (averaging $6 \mathrm{~min} .32 \mathrm{sec}$., s.d. $10 \mathrm{~min} .2 \mathrm{sec}$.). What is interesting is the fact that those working sphere-segments are composed of chains of actions (e.g. telephone calls, interactions) also of very brief duration (averaging $1 \mathrm{~min} .29 \mathrm{sec}$, s.d. 1 min. 25 sec., excluding meetings and lunch). Figure 2 shows a detail of how these chains of actions comprise a segment of a working sphere. This gives a detailed view of how work is fragmented. 


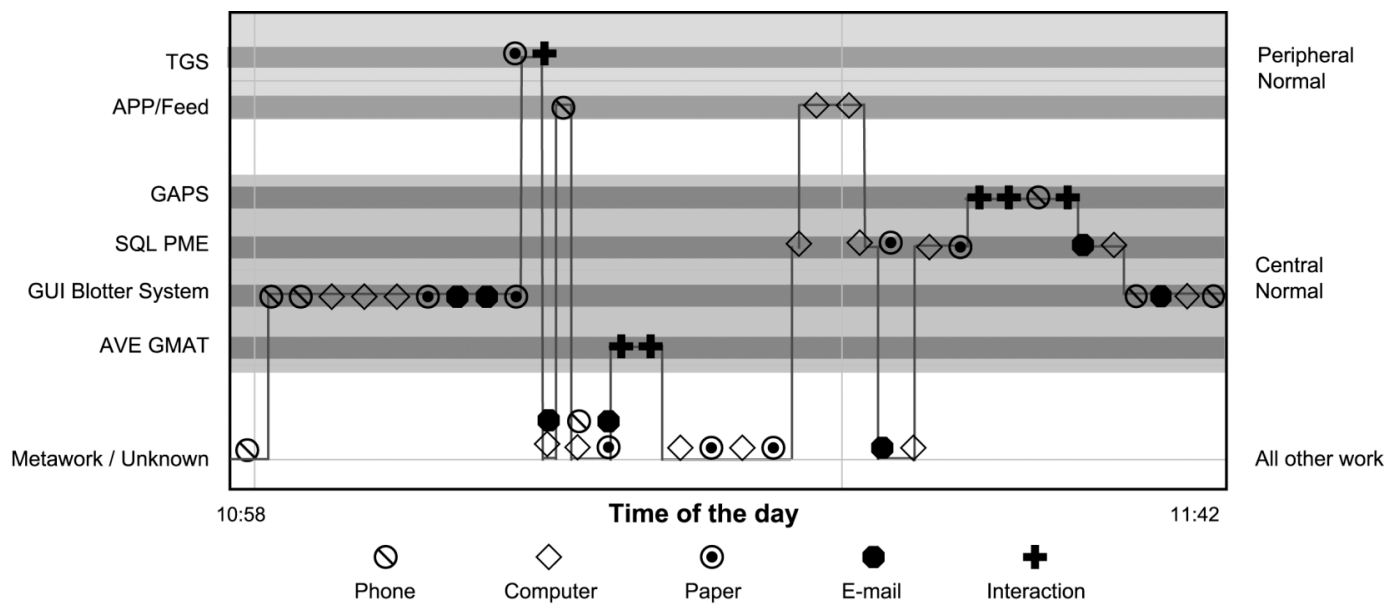

Figure 2. Detail of actions and working spheres (from 10:58 to 11:42 A.M.)

From this description of one of David's mornings, we can identify three important characteristics of multi-tasking. First, we can see that multi-tasking of working spheres is framed by the collaborations established with others. Some collaborations with the same people can involve more than one working sphere. In this scenario, when an individual interacts with others, they might end up talking and multi-tasking among those shared working spheres. For example, because David has a collaboration with Phil that includes multiple working spheres (e.g. the SIGMA initiative, the Bottler-issue and other projects), we observed that while interacting they often jumped from one working sphere to another to discuss different issues. These kinds of collaborations with multiple working spheres impose challenges as people must be prepared to multi-task among them on demand. Consequently, people must manage their work from multiple perspectives: not just in terms of individual and independent working spheres, but also in terms of managing the entire collaboration that frames a set of working spheres.

Second, we can see that multi-tasking often is characterized by spontaneity in the way that working spheres originate and are assigned to people. As we described before, David multi-tasked among working spheres that were expected, as they were in his agenda, and working spheres that arose unexpectedly. Thus, the way that a working sphere is enacted in practice is determined by the circumstances while executing it, but also by the spontaneous way in which working spheres are originated and assigned to one. As the scenario shows, the Blotter-system's issue arose unexpectedly and David had to adjust his plans for that day and to devote attention to solving the problem fast. More importantly, the working sphere was given to David in an informal way and not through any of the formal mechanisms established by ITS to assign work (e.g. a project request form). Hence, we can say that the spontaneous way that characterizes how people get involved in some working spheres shapes the way multi-tasking is done in 
practice. People must constantly adjust priorities and re-define their agendas by including new working spheres "on the fly".

Finally, the scenario serves to highlight that people multi-task among collaborations and working spheres that have different levels of maturation. Working spheres and collaborations are gradually defined as people become aware of the demands of their assignments. Often it is not possible to know all the details of a working sphere initially, such as the level of involvement required, its time frame, outcomes expected, and its collaborative structure. The Blottersystem's working sphere development depicts, in a very time-compressed way, the gradual definition that other collaborations exhibit over longer periods. As we can see in the scenario, the subset of individuals involved in the resolution of the problem with the Blotter-system was gradually defined as David interacted with more people to clarify the problem, defining how and with who it could be solved. Consequently multi-tasking and managing working spheres with different levels of maturation can be challenging as people have to plan and manage work for spheres with well established times frames, resources, and collaborative structures, but also for other spheres for which just partial information exists.

\section{Continual switching of working spheres}

We found that David's involvement with a large number of working spheres and their degree of fragmentation is common among the other informants.

\begin{tabular}{|c|c|c|c|c|c|}
\hline \multicolumn{1}{|c|}{ Type of working sphere } & \multicolumn{2}{c|}{ Central } & \multicolumn{2}{c|}{ Peripheral } & \\
\hline Condition & Normal & Urgent* & Normal & Urgent* & All \\
\hline Avg. \#. W.S. per day & $\mathbf{8 . 7 2}$ & $\mathbf{0 . 9 2}$ & $\mathbf{3 . 0 2}$ & $\mathbf{1 . 0 3}$ & $\mathbf{1 2 . 2 2}$ \\
& 5.06 & 0.70 & 2.35 & 0.78 & 5.30 \\
\hline Avg. Time/W.S. per segment & $\mathbf{0 : 1 1 : 5 7}$ & $\mathbf{0 : 0 8 : 3 6}$ & $\mathbf{0 : 0 5 : 2 4}$ & $\mathbf{0 : 0 4 : 4 1}$ & $\mathbf{0 : 1 0 : 2 9}$ \\
& $0: 04: 00$ & $0: 06: 14$ & $0: 03: 38$ & $0: 04: 52$ & $0: 02: 51$ \\
\hline Avg. Total Time/W.S. per day & $\mathbf{0 : 4 5 : 0 8}$ & $\mathbf{0 : 2 1 : 2 8}$ & $\mathbf{0 : 0 8 : 0 3}$ & $\mathbf{0 : 0 8 : 1 1}$ & $\mathbf{0 : 3 3 : 5 8}$ \\
& $0: 20: 44$ & $0: 16: 08$ & $0: 05: 46$ & $0: 06: 34$ & $0: 12: 04$ \\
\hline
\end{tabular}

Table I. Average number of working spheres (W.S.) and segment durations. Means are in boldface and standard deviations are in normal font. * The data correspond to 27 informants who handled urgent spheres during observation

As table I shows, the information workers that we studied engaged in an average of about 12 working spheres per day. Among those, about nine of them were central working spheres for the individuals while the rest demanded just peripheral involvement. The continuous engagement with each working sphere before switching was very short, as the average working sphere segment lasted about 10.5 minutes. 
The brief involvement in multiple working spheres and their fragmentation is a clear challenge that our informants face everyday. All our informants recognize that they must engage in an explicit effort to keep focused on what they do and, in case of fragmentation, they have to be able to recover and maintain the continuity of the working sphere. There is a struggle to keep focused, as well described by one of our informants, Adam, a financial analyst at ITS, who commented about the characteristics of this effort and compared it as navigating through a river:

"Sometimes you just get going into something and they [call] you and you have to drop everything and go and do something else for a while. But I generally just have a pretty good idea of what is needed to be done, what my major tasks are. And just knowing that, I mean, it is like, it's almost like you are weaving through, it is like, you know, a river, and you are just kind of like: "Oh these things just keep getting in your way", and you are just like: "get out of my way" and then you finally get through some of the other tasks and then you kind of get back, get back along the stream, your tasks, that's a weird analogy [laughs], but there are always currents that kind of take you, tend to take you in another direction, and you just have to know if you should be following that."

The analyst's river analogy reflects that information workers have to make an explicit effort to keep "along the stream" of their working spheres in spite of "currents" that can divert their attention. Moreover, the analogy also reflects that individuals need to maintain a level of awareness about all their major working spheres in order to be able to assess whether they should switch or remain focused on the current working sphere at any particular moment. In the next section we address how in practice our informants enact those efforts to consolidate knowledge about what their "major tasks" are, how they maintain awareness of working spheres other than the one in which they are currently engaged in, and how they efficiently switch among their working spheres as necessary.

\section{Fundamental processes involved in multi-tasking}

We argue that the multi-tasking behaviors observed with our informants can be better understood over time, encompassing past, present and future engagements in working spheres. Over time, working spheres evolve, transform and multiply as individuals identify collaborations and enact purposeful activities with other members of their teams. The course is experienced by individuals, but also shaped by them, as they are actively involved in starting, redirecting and abandoning work efforts. Based on our analysis, we discovered that individuals use three fundamental processes to manage multi-tasking as work moves along its temporal course. These processes involve a constant renewal of overviews of the working spheres in which one is engaged, the adequate maintenance of a flexible window of focus over working spheres demanding attention, and the management of transitions leading to switching among working spheres. These three processes are enacted and combined as individuals move throughout their days, and 
influence, and are influenced by, the collaborations established with others. We draw from our data to illustrate these processes in the following sections.

\section{Continual renewal of overviews}

We argue that to effectively multi-task, people must gain an overview of the working spheres in which they are currently engaged. An overview contains the knowledge about the scope and purposes of a set of working spheres, their temporal constraints, degree of development, and the next actions to conduct in each one. With such an overview, information workers can maintain a state of preparedness; they can make better judgments with respect to their priorities and can move in and out of working spheres as circumstances change or opportunities arise. People might start the first hours of the day by gaining an overview through verification using artifacts, consulting with co-workers, or monitoring communication channels with pending messages. However, given the changing nature of their work, our informants, along their day, continually renew overviews of their working spheres in order to make sure that the current working sphere is the one that must be attended to at that particular moment. A description of how this process occurs can be seen in the experience of Louis, a project leader at ITS:

It is 9:02 a.m., Louis is arriving at the office, and he is checking some reminders from his computer calendar about some meetings he has today. He then opens his e-mail inbox to check for messages. "Nothing new, nothing new", he mumbles as he scrolls down the list with a 3line summary of each message. Suddenly he stops at one of them "Oops! This one". He looks at the message content briefly. "OK, let's see, what else?" he says as he continues checking the list of messages. Finishing that, he turns over a small paper notebook on the left side of his desk. "My notebook with the day-to-day stuff" he says, as he starts making annotations on it and turning over previous pages, "moving some items", he says. As he annotates on his notebook a list of items to complete today, he turns over a whiteboard hanging on one of the walls. On the whiteboard, he also has a list of things: "Those are like my bigger projects and the things I have to do". At 9:12 a.m., he turns to his computer, takes the phone and starts dealing with one of the items listed in his notebook. During the next two hours, he works on different items, leaves the cubicle a couple of times, and makes a few phone calls. At 11:14 a.m. he comes back from a meeting with George, his boss, and while taking his notebook and looking at it he says: "OK I took care of one thing, but for this one George has other plans. Let's hold that one". He leaves the cubicle again to talk to other people and defines details for another project. Louis continues his day attending to some meetings, preparing a report for people in Munich, and covering other items listed in his notebook. At the end of the day and just before leaving, he takes a look at his notebook, checks his annotations, and then turns over the whiteboard and makes some changes. He mumbles: "Things are cooking".

As we can see in the scenario, people gain an overview of their working spheres through a process that consolidates information from many different sources. In Louis' case, this process includes consulting information in his notebook, checking his whiteboard, and going through summaries of his e-mail messages. We found that other informants use agendas, daily planners, or other artifacts either in paper or in digital form for the same purpose. 
Furthermore, the scenario highlights that to manage their multi-tasking, individuals represent information about their working spheres with different levels of aggregation using both digital and physical artifacts. Overviews can provide local or global perspectives of the working spheres depending on the level of aggregation. A local perspective refers to the day-to-day things that people must do. Louis used a notebook to maintain a list of particular actions to be done in the following days (e.g. making phone calls, preparing reports, asking someone a question, etc.). In parallel, people also maintain a global perspective of their working spheres and as one informant indicated, this provides them with: "the big picture of things that I am suppose to be working on". In Louis' case, this global perspective was maintained in his whiteboard. Although Louis primarily uses two physical artifacts to manage his working spheres (notebook and whiteboard), he complements them with digital tools such as his electronic calendar. In contrast, we found other informants relying more on digital information systems as their jobs revolve around them. Such is the case of developers or analysts who commonly use systems to keep track of their software items to be developed or tested in a particular release. Reports from those systems help keep people informed on what they are supposed to do each day.

The role of collaborations that individuals establish with others is central to understanding the mechanisms that generate overviews. To some extent, as we have discussed, gaining an overview is based on a person's effort to individually articulate their own work (i.e. defining what should be done, with what resources, the timeline, etc.). However, it is also clear that any individual overview originates first as a product of articulating the work collectively (Strauss 1985). Consequently, when individuals gain an overview, identifying the working spheres and setting priorities, they do so by aligning their overview to the overall goals that the collective effort aims to achieve. We observed that this alignment of overviews of their working spheres gets done in practice through formal and informal interactions with collaborating partners (cf Strauss 1985).

Through formal meetings, individuals can acquire information on the status of others' working spheres which helps consolidate their own overview. Meetings with the specific purpose of keeping people "on the same page" were very common at ITS and Venture as they allowed people to establish a common ground, refresh their collaborations, define dependencies, articulate their work, and discuss and validate their priorities with others. To some extent, those meetings also helped people anticipate the multi-tasking that they would be likely to experience through their collaborations. For example, an analyst mentioned that knowing what components the developers were involved in enabled her to plan in advance the testing of those components. This freed her from other timeconsuming tasks on those days so she could be more responsive to the developers.

In contrast with formal team-based initiatives, we also found that overviews can be formed by individuals in a more informal way. We noticed that with 
certain regularity some of our informants "visit" people in their own team and in other teams to chat informally and get updated about their work and changes on it. This practice is explained by Albert, a senior developer at ITS:

"I try to talk with the systems guys, Joe's group. Keep up with what they are doing. And I try to talk with the UNIX guys, keep up with what they are doing... if I spent an hour going around talking to people, that's really productive for me in getting my work done, because I found out what's going on and I can anticipate change and be very much more productive that way."

Thus, a typical day of our informants is characterized by a continual renewal of overviews of their entire set of working spheres. People update their overviews continually, through communication channels such as face-to-face interactions, email or voice mail, or by updating their reports in systems. Overviews are not only updated but also validated through interactions with other people, either formally or informally.

\section{Maintaining a flexible window of focus}

A flexible window of focus refers to the ability of individuals to be immersed and attending to a particular working sphere, but at the same time, to be flexible and able to focus on things around them that can affect their other working spheres. As other authors have noticed (cf Heath and Luff 1991), we observed that our informants, while conducting their work, monitor the actions of their co-workers, checking their progress and status, as this helps them to adjust their own actions. However, we also observed that while monitoring, individuals focus their attention flexibly to filter and seek information relevant for their working spheres.

We found that the window of focus expands to cover both their active and potential working spheres. On one hand, based on their overviews, the individuals have a number of active working spheres that can draw their attention. Consequently, while conducting work in one of them, their focus is also partially oriented towards other working spheres. We noticed that people, as part of the process of creating their overviews, can develop a set of expectations in regards to the particular events or conditions that they should monitor that relate to those spheres (e.g. a person with whom they must talk, a device that has to be available, a paper format that has to be received, etc). Those events act as triggers that guide the multi-tasking among their active working spheres. On the other hand, we observed that because working spheres can arise unexpectedly, individuals attend to events that can have a direct impact on their areas of responsibilities and potentially, can become working spheres for them (e.g. problems on systems they supervise or requests from clients). By keeping a flexible window of focus over their areas of responsibility, they are able to cope with the unexpected way in which some of their working spheres originate and are assigned. Thus, as individuals conduct their work, both active and potential working spheres are focused on and distractions are filtered that have no relationship to their work. 
The following scenario shows how the process of maintaining a flexible window of focus is experienced by John, a developer at ITS.

Today John is working against the clock. It is 11:18 a.m. and he is busy writing the documentation of the software code for the Upload process. He has been working on this working sphere for the last two weeks but, as he has been involved in other urgent working spheres, he is delayed. Yesterday he attempted to negotiate an extension of the deadline with his boss Leo, but he was not successful. The report of the Upload process has to be on Leo's desk at 9:00 a.m. tomorrow morning. As he works, he wears his headphones and plays some music, "Music helps me to focus", he mentions. After some time working he turns the volume down as he notices that Leo, who sits in an adjacent cubicle, is on the phone with the client. He stops working and listens to the conversation. However, as it seems that Leo's conversation is not really relevant for him, he continues preparing the report. At 11:55 a.m., Chris shows up and asks if John has plans for lunch. "I will order something, I have to get done with this report", says John and continues working. One hour later, while still working on the report, he listens to a conversation in James' cubicle as he talks to Eric about one of the software systems that John is supporting. He stops typing, takes out his earphones, and walks over to James' cubicle: "No James, you need a patch for that software". After discussing the patch that James has to install in the system, he returns to his cubicle and continues his work on the report.

In the scenario we can see how John listened and attended to matters that were related to his working spheres. He had to balance his focus over his current working sphere (i.e. the Upload process) with conversations happening around him. Similarly, John reacted to things that had no relation to his active working spheres, but that did have a direct impact on their areas of responsibility. For instance, while listening to James talking about a system that John was responsible for, John decided to focus on that conversation and clarified to James that he had to install a software patch for the system. This issue was unexpected and was not part of John's overview, yet it became a working sphere that he attended to that day, as it concerned his responsibility.

Maintaining a flexible window of focus requires that individuals be connected to the collective environment. As we observed in John's scenario, although he wore headphones and played music he kept listening to things around him and remained aware of the larger environment outside of his office. Beyond the events that occur nearby, other channels help individuals be connected to more distant events (e.g. e-mails, instant messaging, the phone or voice messages). We observed that the actual determination of the channels that individuals leave open depend on the communication requirements of both their active and potential working spheres. Based on the overviews of their active working spheres, our informants can expect that some communication channels convey information about particular spheres and therefore this affects their decision to leave them open. For example, some informants at Venture, while waiting to get calls from clients about approval of contracts, kept their cell phones on and handy as clients were likely to call their cell phone numbers. Also, based on their responsibilities, individuals rely on particular communication channels through which potential working spheres can emerge. For example, many of our informants play some 
role supporting users, and they had to always attend to phone calls from customers as those can be related to problems in the systems they support. We also noticed that given certain conditions, such as an approaching deadline, people can opt for closing most channels and even leave the office for a day or two and work from home. When co-workers were aware that the individual was working on a deadline, they helped her by limiting their interactions with her.

Thus, we observed that as individuals switch working spheres, they maintain a flexible window of focus over external events. The choice of whether to attend to an event is based on both its relevance for one's current working sphere, and one's overall responsibilities.

\section{Management of transitions}

The management of transitions refers to the strategies used by information workers to facilitate their reorientation and engagement to a working sphere when moving from one working sphere to another. We observed that our informants experience different types of transitions that vary according to the way those working spheres intersect in time. Intersections can often result on challenges to resume working spheres later on and managing those transitions is important.

We found that our informants experienced natural transitions when an action is concluded (e.g. a phone conversation or the composition of an e-mail message) and no further action is required in that particular working sphere at that moment (e.g. the individual has to wait for a response from another person). In those cases, we noticed that in general, individuals try to reach a point of closure for their working sphere: making sure that nothing else has to be done, annotating details on documents, or putting away folders or documents associated with it. We observed that many times after a natural transition, individuals switched to another working sphere without interacting with any artifact or person to give them an overview. Other times, they renewed their overviews, by checking their e-mail for new or pending messages, went through their lists (e.g. to-do lists, agendas, etc) or even sought updates from co-workers. Once the overview was gained the individual moved to the next working sphere.

Many times our informants experienced forced transitions as a result of interruptions of one's current working sphere. In those situations people have to leave the current working sphere and turn to something else. We observed that a common mechanism to manage this transition is based on extending work in the current working sphere until a natural breaking point is reached. In this case, individuals, when interrupted by others, request them to wait so they could conclude the current action (e.g. finishing composing an e-mail message or typing a line of software code) and then give them their full attention. This strategy aims to minimize the level of disruption in the current working sphere by guaranteeing that it is left at a natural breaking point so that it can be easily resumed. Many of 
our informants pointed out that reaching natural breaking points was necessary in order to avoid losing track of the flow of ideas so as to be fully attentive to the interrupting working sphere.

We identified two main ways our informants managed abrupt transitions with respect to the immediate involvement in the interrupting working sphere. In many cases individuals accepted interrupting work and became fully involved in it until the request was done. This kind of involvement is typical when urgent working spheres serve as the basis for interruptions. These urgent spheres can have strong implications, for example, when requests refer to problems with financial transactions or legal operations. In contrast, in many cases, individuals opted for another strategy: they responded quickly to an interruption, took the necessary information and details about the request, and then followed it up later when they could easily turn away from other working spheres. This partial involvement helped them to be responsive and organize their work in a better way, but at the same time, allowed them to continue with the interrupted working sphere after a brief period, as is explained by Ronald a manager at ITS:

“...somebody called me and asked me a question I need to do research for and get back to them. I'll note it here [Outlook Tasks] so that I make sure that I don't forget. So when I get periods during the day when, 'OK I don't have any meetings', 'developers are all busy', this and that, I'll look here and see what I need to address."

We found that during interactions with another, our informants experienced sequential transitions among many working spheres as they discussed issues related to each one. We noticed this happening during conversations prior to the start of a formal meeting and in other kinds of informal interactions. Individuals took advantage of interruptions by people with whom they shared different working spheres by purposely engaging in sequential transitions. After talking about the interrupting working spheres, people tried to discuss other pending working spheres before the interaction finished. The following scenario illustrates that situation:

While working on an analysis, Jennifer is interrupted by the phone ringing: "Hello?... Hi Pam!". Pam, a trainer in Texas, is calling to give details about the training program at GTE, a new medical practice, as Jennifer called her earlier this week. However, Jennifer already has the information: "Don't worry Pam. I actually ended up figuring out that one," says Jennifer. They talk about that but then Jennifer turns to another working sphere, "What about East Bay Orthopedics? Are they signing the contract?". After discussing about East Bay, she ends the phone call and resumes work on her analysis.

We identified that in the case of abrupt transitions, individuals opted for different strategies to resume work. In some situations, the resumption is straightforward as people remember enough cues to facilitate the recovery. In other cases, we observed that if people have enough time before switching, they use post-it notes to annotate details that are useful for resuming the working sphere later on. Other informants annotated the actions performed for the working sphere as these were conducted. This indicates that people were preparing for 
interruptions; when they happened they could figure out where the work was stopped and could easily resume work in it. Finally, we also observed that many of our informants tried to recreate the last actions they did before the interruption. They went through each of the open applications in their computers or looked at the different documents on their desk trying to regain their train of thought.

\section{Discussion}

Understanding how information workers multi-task is fundamental for CSCW. Collaborations in practice are experienced as the intertwining of multiple working spheres, where people, along the course of the day, move in and out of different collaborative contexts based on circumstances. Furthermore, collaborations arise, evolve, and are defined in a situated manner as people delineate their work moment by moment and identify the subset of individuals that can contribute to achieve the purposes of their working spheres (Suchman 1987). Consequently, understanding the basic processes and strategies used in multi-tasking contributes toward understanding collaborative work itself.

The three fundamental processes that we identified highlight some optimal ways by which multi-tasking is achieved, as an informant described, to "don't let anything fall through the cracks". It should be clear that although each process is relevant for all our informants, we observed that the specific use of one or another strategy is based on personal preferences, job's characteristics, or the availability of resources. For example, to represent their overviews, some informants were more inclined towards annotating their working spheres in "to-do" lists, whereas others just used their email inboxes to list pending messages related to working spheres. Similarly, some types of job roles (e.g. project leaders) demanded more interdependence and required more interaction with others, whereas other work tended to be more solo. In some other cases individuals had access to particular tools such as instant messaging that facilitated awareness of the presence of coworkers beyond what can be understood by just listening to events in the hallway or other cubicles. Based on our findings, we discuss some of the challenges to support the different processes we discussed that are involved in multi-tasking.

Maintaining an overview of the working spheres in which one is engaged is based on the constant integration of information from many sources including digital and physical artifacts. People consolidate such information and use it to develop global and local perspectives of their working spheres. Local perspectives, containing those day-to-day actions to be done for their working spheres, were often represented in artifacts that are mobile (e.g. notepads), that afford flexible schemes to annotate information, that provide a space to draw on and discuss ideas with others, and that were often left open and visible on desks to serve as easy reminders of pending actions. On the other hand, global perspectives contained more high-level descriptions of working spheres and were 
always visible and represented in either whiteboards or printouts hanging on walls, or easily reachable on desks. We argue that technological support should be oriented towards helping individuals maintain both local and global perspectives of their working spheres, providing the ability to represent information in portable devices that can be located on their desks or hung on walls, and be connected and synchronized with other tools such as email, electronic calendars, or other systems. Similarly, those technologies can serve to link and share information about the progress that individuals have in their personal working spheres to the systems used by the organization to manage and coordinate team projects or manage customer requests.

Another challenge is for individuals to maintain a flexible window of focus over their different working spheres. There are clear limits on the degree to which individuals can monitor events around them. Consequently, technology can play a very important role in providing individuals with an expanded focus to be aware of events that might affect both current and pending working spheres. For this purpose, awareness information mechanisms should be designed to be configurable to reflect not only the status of collaborations, but also the status of particular working spheres in those collaborations (e.g. if a phone call was made, a document was signed or resources are available).

Finally, adequate tools do not exist to support transitioning between different working spheres. We argue that, due to the interactive nature of work, technologies should not only be oriented to reduce transitions due to interruptions, for instance by identifying when is appropriate to interrupt (Adamczyk and Bailey 2004), but, more importantly, oriented to make transitions beneficial for individuals. We argue that transitions due to interruptions can be optimized if individuals can remember and discuss those pending issues that they have with the persons interrupting them. We noticed that, lacking automated support for quickly retrieving information about shared working spheres and pending issues, our informants just opted to check their paper "to-do" lists, agendas, or mailboxes to verify if there are other pending issues. However, our informants commented that many times it was after the person was gone that they remembered those other things they needed to discuss with the interrupters. Technology should provide mechanisms to generate summaries of pending issues in working spheres so that interactions are optimized.

\section{Conclusions}

In this paper we have presented a view of collaborations that is different from that usually described in CSCW studies. We view that people are involved in multiple working spheres involving different sets of people and they continually change working spheres and collaborative contexts throughout the day. Work is thus very fragmented. We identified that our informants manage their multi-tasking by 
renewing their overviews, by maintaining a flexible focus on information relevant to current and future working spheres, and by managing transitions among their working spheres. We discussed how those processes can be supported by technology, and emphasized the importance of integrating information used to organize personal work with organizational information at the collective level. Our findings reflect and build upon previous CSCW studies, but also provide new perspectives to understand multitasking with multiple collaborations. We plan to conduct further analysis of our data to refine and improve our understanding.

\section{Acknowledgments}

We would like to thank all our informants at ITS and Venture. This research was supported by the National Science Foundation under grant no. 0093496, by the Center for Research on Information Technology and Organizations, and with grants from CONACYT and UCMEXUS.

\section{References}

Ackerman, M., D. Hindus, S. D. Mainwating and B. Starr (1997): 'Hanging on the wire: A field study on an audio-only media space', ACM Transactions on Computer Human Interaction, vol. 4, no.1, 1997, pp. 39-66.

Adamczyk, P. D. and B. P. Bailey (2004): 'If not now, when?: The effects of interruption at different moments within task execution' in: Proceedings of CHI 2004, ACM press, Vienna, Austria, pp. 271-278.

Belloti, V., B. Dalal, N. Good, P. Flynn, D. Bobrow and N. Ducheneaut (2004): 'What a To-Do: Studies of Task Management Towards the Design of a Personal Task List Manager' in: Proceedings of CHI 2004, ACM Press, Vienna, Austria, pp. 735-742.

Belloti, V., N. Ducheneaut, M. Howard and I. Smith (2003): 'Taking email to task: the design and evaluation of a task management centered email tool.' in: ACM Conference on Human Factors in Computing Systems (CHI 2003), ACM, Fort Lauderdale; FL., pp. 345-352.

Blandford, A. E. and T. R. G. Green (2001): 'Group and individual time management tools: what you get is not what you need', Personal and Ubiquitous Computing, vol. 5, no.4, December 2001, pp. 213-230.

Boardman, R. and A. M. Sasse (2004): "'Stuff goes into the computer and doesn't come out" A cross-tool study of personal information management' in: Proceedings of CHI 2004, ACM press, Vienna, Austria, pp. 583-590.

Buscher, M., P. Mogensen, D. Shapiro and I. Wagner (1999): 'The Manufaktur: supporting work practice in (landscape) architecture' in: Proceedings of the Sixth European conference on Computer supported cooperative work, Kluwer Academic Publishers, Copenhagen, Denmark, pp. 21-40.

Czerwinski, M., E. Horvitz and S. Wilhite (2004): 'A Diary Study of Task Switching and Interruptions' in: Proceedings of CHI 2004, ACM Press, Vienna, Austria, pp. 175-182.

DiMaggio, P. (2001). The Futures of Business Organization and Paradoxes of Change. The Twenty-First-Century Firm: Changing economic organization in international perspective. P. DiMaggio. Oxford, Princeton University Press: 210-244. 
Fussell, S. R., S. Kiesler, L. D. Setlock, P. Scupelli and S. Weisband (2004): 'Effects of Instant Messaging on the Management of Multiple Project Trajectories' in: Proceedings of CHI 2004, ACM Press, Vienna, Austria, pp. 191-198.

González, V. and G. Mark (2004): '"Constant, Constant, Multi-tasking Craziness": Managing Multiple Working Spheres' in: Proceedings of CHI 2004, ACM Press, Vienna, Austria, pp. 113-120.

Heath, C. and P. Luff (1991): 'Collaborative activity and technological design: Task coordination in London Underground control rooms' in: Proceedings of ECSCW 91, Kluwer Academic Publishers, Dordrecht, The Netherlands, pp. 65-80.

Hudson, J. M., J. Christensen, W. A. Kellogg and T. Erickson (2002): '"I'd Be Overwhelmed, But It's Just One More Thing to Do:" Availability and Interruption in Research Management.' in: Proceedings of CHI 2002, Minneapolis, Minnesota, pp. 97-104.

Kraut, R. E., R. Fish, R. Root and B. Chalfonte (1993). Informal communication in organizations: form, function, and technology. Groupware and Computer-Supported Co-operative Work. R. Baecker, Morgan Kaufmann, 1993: 287-314.

Leont'ev, A. (1978): Activity, Consciousness, and Personality. Englewood Cliffs, N.J., PrenticeHall.

Mark, G., V. González and J. Harris (2005): 'No Task Left Behind? Examining the Nature of Fragmented Work' in: Proceedings of ACM CHI 2005, ACM press, Portland, OR, pp. 321330.

Mark, G., J. Grudin and S. Poltrock (1999): 'Meeting at the desktop: An empirical study of virtually collocated team' in: Proceedings of ECSCW'99, ACM press, Copenhagen, pp. 159178.

Mintzberg, H. (1973): The Nature of Managerial Work. Englewood Cliffs N.J., Prentice Hall.

O'Conaill, B. and D. Frohlich (1995): 'Timespace in the Workplace: Dealing with Interruptions' in: Proceedings of CHI 95, ACM, Denver, Colorado, pp. 262-263.

Perlow, L. A. (1999): 'The Time Famine: Toward a Sociology of Work Time', Administrative Science Quarterly, vol. 44, 1999, pp. 57-81.

Rogers, Y. (1994): 'Exploring Obstacle: Integrating CSCW in evolving organizations' in: Proceedings of CSCW 94, ACM Press, Chapel Hill, N.C., USA, pp. 67-77.

Rouncefield, M., J. A. Hughes, T. Rodden and S. Viller (1994): 'Working with "Constant Interruption": CSCW and the Small Office' in: Proceedings of CSCW 94, ACM, Chapel Hill, N.C., pp. 275-286.

Sproull, L. S. (1984): 'The Nature of Managerial Attention', Advances in Information Processing in Organizations, vol. 1, 1984, pp. 9-27.

Strauss, A. (1985): 'Work and the division of labor', The Sociological Quarterly, vol. 26, no.1, 1985, pp. 1-19.

Strauss, A. and J. Corbin (1998): Basics of Qualitative Research: Techniques and procedures for developing grounded theory, Sage.

Suchman, L. (1987): Plans and Situated Actions: The problem of human machine communication. Cambridge, Cambridge University Press.

Suchman, L. and E. Wynn (1984): 'Procedures and Problems in the Office', Office: Technology and People, vol. 2, pp. 133-154.

Whittaker, S., D. Frohlich and O. Daly-Jones (1994): 'Informal workplace communication: What is it like and how might we support it?' in: Proceedings of CHI 94, ACM, Boston, Massachusetts, pp. 131-137. 